\title{
Money Laundering and FATF Compliance by the International Community
}

\author{
Ali Alkaabi, George Mohay, Adrian McCullagh, and Nicholas Chantler \\ Information Security Institute, Queensland University of Technology, GPO Box 2434, \\ 126 Margaret Street, Brisbane, QLD 4001, Australia \\ a.alkaabi@isi.qut.edu.au, g.mohay@qut.edu.au, \\ a.mccullagh@qut.edu.au, a.chantler@qut.edu.au
}

\begin{abstract}
This paper examines the anti-money laundering systems of Australia, the United Arab Emirates (UAE), the United Kingdom (UK) and the United States of America (USA), the extent to which they have implemented the Financial Action Task Force (FATF) recommendations, and how compliance with these recommendations is affected by local cultural and economic factors. The paper makes use of FATF evaluation reports to compare the countries' compliance; it examines some of the underlying cultural considerations and culturespecific ethical issues that affect the extent of compliance, and how cultural and ethical considerations may affect good governance. The findings indicate that the UK and the USA are the most advanced with regards to their compliance with the FATF recommendations and Australia and the UAE less so. The UAE is in particular found to be least compliant. We relate this finding to previous work on how a country's legal and financial systems develop in line with its religion, culture and socio-economic situation, and examine how such local factors have affected the UAE's financial and anti-money laundering and combating the financing of terrorism (AML/CFT) systems. This research will be of interest to policy-makers and government agencies involved in addressing money laundering and its successful detection and prosecution.
\end{abstract}

Keywords: Money Laundering, FATF, Compliance, Australia, UAE, UK, USA.

\section{Introduction}

There are, generally speaking, two reasons why organisations and individuals may wish to launder money. First, to hide illegitimately acquired income or to avoid divulging activities which if closely scrutinised might reveal related illegal activities. Second, to hide legitimate income in order to avoid income tax in countries in which it is levied. If the extent of money laundering is extreme, then this represents a substantial threat to the revenue and economy of a country and possibly an untenable level of (probably organised) criminal activity. Therefore, it is in society's interests to detect money laundering. Prevention of money laundering will arguably prevent loss of government revenue and will likely prevent or at least reduce criminal activity. 
Consequently, countries worldwide have legislated against money laundering. At the international level, the Financial Action Task Force (FATF) developed the 40+9 recommendations on anti-money laundering and combating the financing of terrorism (AML/CFT) [1] in an attempt to provide a good governance framework. These 40+9 recommendations are generally recognised as an international standard for implementing any AML/CFT system. Countries such as Australia, the UAE, the UK and the USA have reformulated their legislation and regulations to bring them into line with the FATF recommendations. Interestingly, these four countries among others have been identified by the United States' (US) Department of State as major money laundering countries in 2008 [2]. To the authors knowledge this paper will be the first paper that compares a modern Islamic country such as the UAE with three modern western jurisdictions such as Australia, the UK and the USA.

The work described in this paper focuses on these four countries for a number of reasons. The UAE has been selected as the funding for this research has been provided by the $\mathrm{UAE}^{1}$ and because the $\mathrm{UAE}$, while a modern and rapidly developing economy, is an Islamic jurisdiction and thus to that extent distinctly different from the other three countries. Australia is included as the research has been undertaken in Australia while the UK has been selected because it is a jurisdiction representative of the European Community. Finally, the USA has been selected for a number of reasons, the principal being that as the world's largest economy it needs to be included in any study of this sort.

This paper analyses the differences in the AML/CFT systems of Australia, the UAE, the UK and the USA, and the extent to which they have interpreted and remained faithful to the FATF recommendations. The paper makes use of the FATF evaluation reports for Australia in 2005 [3], the UAE in 2007 [4], the UK in 2006 [5] and 2009 [6] and the USA in 2006 [7] to compare their compliance and discusses the local factors, such as cultural and economic factors, that have arguably affected the UAE's compliance with the FATF recommendations.

Section 2 analyses and compares the extent of compliance of these countries with the FATF recommendations. It also discusses the implications for non-compliant countries. Section 3 analyses how local factors have arguably affected the UAE's compliance with the FATF recommendations. Section 4 presents our conclusions.

\section{Compliance with the FATF 40+9 Recommendations}

In the recent FATF evaluation of their AML/CFT systems, countries were required to submit follow-up reports indicating their progress with achieving compliance. Australia, the UK and the USA have reported back to the FATF. The only published follow-up report arising from these evaluations is one for the UK AML/CFT system which shows that the UK system has made substantial progress and has reached a satisfactory level of compliance with all the core and key recommendations ${ }^{2}$ including recommendation 5, which concerns "customer due diligence and record-keeping". Follow-up reports for Australia and the USA are not available in the public domain at

\footnotetext{
${ }^{1}$ This research is funded by the Abu Dhabi Police, UAE.

${ }^{2}$ According to the FATF, the core recommendations are 1, 5, 10, 13, SR II, and SR IV, and the key recommendations are 3, 4, 23, 26, 35, 36, 40, SR I, SR III and SR V.
} 
the time of writing. The UAE was to report to the FATF in March, 2010. Compliance with FATF recommendations is rated as follows: fully compliant (C), largely compliant (LC), partially compliant (PC) and non-compliant (NC). Compliance with each recommendation is measured against essential assessment criteria. This section compares how Australia, the UAE, the UK and the USA comply with the FATF 40 recommendations (see Table 1). The section then proceeds to compare how these four countries comply with the FATF 9 special recommendations (see Table 2).

\subsection{Compliance with the FATF 40 Recommendations}

The FATF 40 recommendations on AML are categorised into four groups: (a) legal systems; (b) preventive measures; (c) institutional and other measures; and (d) international co-operation.

Legal systems. The UK and the USA are fully or largely compliant with 'Legal systems' recommendations 1,2 and 3. The UAE is largely compliant with two recommendations; however, it is only partially compliant with recommendation 1 concerning money laundering offences. The FATF [4] indicated that the UAE has criminalised money laundering but the predicate offences in the law do not cover all types of serious offences such as drug trafficking and corruption, which is not completely in accordance with the FATF recommendations.

Preventive measures. Australia is non-compliant with nine of the 22 recommendations, and is only partially compliant with 8 other recommendations and in particular is noncompliant with the core recommendation 5 regarding customer due diligence. The FATF [3] noted that its customer due diligence is limited in its extent by not covering all varieties of financial institutions. Australia is only partially compliant with core recommendation 10 (record keeping) and key recommendation 23 (financial sector supervision). The FATF noted that the AML/CFT (referred to as AML/CTF in Australia) supervisory system is not in accordance with its recommendations in relation to ensuring that financial institutions have an effective AML/CFT programme in place.

The UAE is non-compliant with core recommendations 5 (customer due diligence) and 13 (suspicious transaction reporting), and it is only partially compliant with key recommendation 23. The FATF noted that there is no core customer due diligence obligations in any law or regulation of the UAE. It also found that there is no requirement in UAE law or regulation to report suspicious transactions related to financing of terrorism. The FATF found that there is a lack of a defined basis to recognise a transaction as suspicious. These deficiencies may in part be the result of the fact that UAE law does not impose customer due diligence obligations and does not clarify the UAE's Financial Intelligence Unit (FIU) responsibilities.

The UK is largely or fully compliant with all core and key recommendations that address 'Preventive measures'. However, it is non-compliant with recommendations 6, 7 and 22 from this group. The FATF [5] indicated that there are no requirements within the UK AML/CFT system concerning the identification of politically exposed persons and noted that there are no requirements specified for financial institutions to collect information with regards to correspondent banking.

In addition to being non-compliant with recommendations 12 and 16, the USA is only partially compliant with recommendation 5 concerning the establishment of 
customer due diligence. The FATF [7] found that there are no requirements for some cash dealers such as life insurance agents to establish customer due diligence, and generally there are no clear requirements to perform ongoing customer due diligence.

Institutional and other measures. With regards to 'Institutional and other measures' recommendations 26-34, Australia is partially compliant with recommendations 29 and 34. The FATF noted that Australian Transaction Reports and Analysis Centre (AUSTRAC) powers of enforcement are limited to criminal sanctions and appear to be rarely applied. While the AML/CFT system of Australia has some problems in compliance with the previous recommendations, it is fully compliant with key recommendation 26. In contrast, the UAE system is partially compliant with recommendation 26 concerning the FIU. The FATF found that the UAE's FIU has some problems in relation to collecting, analysing and disseminating suspicious activity reports. The FATF also noted that the UAE's FIU does not publish annual reports with statistics concerning its activities. It is difficult to find information in relation to the number of suspicious transactions reported each year in the UAE, as we found in a separate work [8]. The UK AML/CFT system is partially compliant with recommendations 33 and 34 . The FATF noted that the UK system does not have sufficient measures to identify accurate information concerning beneficial ownership ${ }^{3}$. The USA AML/CFT system has some problems in compliance with recommendations 33 and 34. The FATF indicated that the US system does not have adequate measures in place to make sure that there is accurate information available in relation to the beneficial ownership.

International co-operation. With regards to recommendations $35-40$, Australia, the UK and the USA are fully or largely compliant with these recommendations. In contrast, the UAE is less compliant than the other countries. It is partially compliant with recommendations 38 and key recommendation 40. It is expected that the UAE will address these areas of deficiencies. The main deficiency is that there are no legal provisions that define how confidential information will be shared with other foreign counterparts.

In summary, and as shown in Table 1, the USA followed by the UK appear to be most advanced in terms of compliance with the FATF 40 recommendations, with the UAE being least compliant.

Table 1. Summary of compliance with the FATF 40 recommendations on AML

\begin{tabular}{|c|c|c|c|c|c|c|}
\hline Country & $\begin{array}{l}\text { Fully } \\
\text { compliant (C) }\end{array}$ & $\begin{array}{l}\text { Largely } \\
\text { compliant (LC) }\end{array}$ & $\begin{array}{l}\text { Total } \\
(\mathrm{C}+\mathrm{LC})\end{array}$ & $\begin{array}{l}\text { Partially } \\
\text { compliant (PC) }\end{array}$ & $\begin{array}{l}\text { Non } \\
(\mathrm{NC})\end{array}$ & $\begin{array}{l}\text { Total } \\
(\mathrm{PC}+\mathrm{NC})\end{array}$ \\
\hline Australia & 12 & 9 & 21 & 10 & 9 & 19 \\
\hline UAE & 5 & 12 & 17 & 16 & 7 & 23 \\
\hline UK & 19 & 10 & 29 & 8 & 3 & 11 \\
\hline USA & 12 & 22 & 34 & 2 & 4 & 6 \\
\hline
\end{tabular}

\footnotetext{
${ }^{3}$ By beneficial ownership it is meant the enjoyment by anyone who has the benefits of ownership of a security or a property and yet nominally does not own the actual asset.
} 


\subsection{Compliance with the FATF 9 Special Recommendations}

This section compares compliance with the FATF 9 special recommendations on Combating Financing of Terrorism (CFT). The FATF simultaneously evaluated the CFT and Anti-Money Laundering (AML) systems in Australia, the UAE, the UK and the USA. Table 2 illustrates a summary by country of compliance with the FATF 9 special recommendations on CFT. Once again, the USA followed by the UK appear to be most advanced in terms of compliance, with the UAE being least compliant.

Table 2. Summary of compliance with the FATF 9 special recommendations on CFT

\begin{tabular}{|c|c|c|c|c|c|c|c|}
\hline Country & $\begin{array}{l}\text { Fully } \\
\text { compliant (C) }\end{array}$ & $\begin{array}{l}\text { Largely } \\
\text { compliant (LC) }\end{array}$ & $\begin{array}{l}\text { Total } \\
(\mathrm{C}+\mathrm{LC})\end{array}$ & $\begin{array}{l}\text { Partially } \\
\text { compliant (PC) }\end{array}$ & $\begin{array}{l}\text { Non c } \\
\text { (NC) }\end{array}$ & compliant 7 & $\begin{array}{l}\text { Total } \\
(\mathrm{PC}+\mathrm{NC})\end{array}$ \\
\hline Australia & - & 5 & 5 & 3 & & 1 & 4 \\
\hline UAE & - & 3 & 3 & 2 & & 4 & 6 \\
\hline UK & 5 & 3 & 8 & 1 & & - & 1 \\
\hline USA & 3 & 6 & 9 & - & & - & - \\
\hline
\end{tabular}

Australia, the UK and the USA are either compliant or largely compliant with the core and key special recommendations. In contrast, the UAE is non-compliant with core special recommendation IV concerning suspicious transaction reporting. The UAE is only partially compliant with the key special recommendation I regarding implementing the 1999 UN International Convention for the Suppression of the Financing of Terrorism, and the key special recommendation III regarding imposing effective laws for freezing and confiscation of funds used for financing of terrorism.

\subsection{Implications of Non-compliance with FATF}

Overall, Australia is non-compliant or partially compliant with three core and key recommendations $(5,10$ and 23$)$. The UAE is non-compliant or partially compliant with nine core and key recommendations $(1,5,13,23,26,40$, SR I, SR III and SR IV). The USA is only partially compliant with core recommendation 5. This finding suggests that there are additional steps that need to be taken by Australia, the UAE and the USA to address the identified deficiencies. The UAE, in particular, needs to do more work to ensure that its AML/CFT system is effectively implemented in accordance with the FATF recommendations.

Non-compliance with the FATF recommendations has negative implications for a country and its relations with other countries. The implications of non-compliance include the increased risk of exploiting a country's financial system for criminal purposes by organised criminals and terrorists, with consequent implications for a country's economy, society and victims of crime [52]. There are also specific implications of non-compliance with respect to dealing with countries which are compliant. To protect its interests and minimise risk, a compliant country may impose tough regulations in dealing with non-compliant countries. A non-compliant country can face obstacles from international organisations and other compliant countries, obstacles such as discouraging foreign investment, trade and relationships, and damaging reputations with international organisations such as the World Bank and the International 
Monetary Fund (IMF). The IMF (2009) [9] noted that "money laundering and terrorist financing activities can undermine the integrity and stability of financial institutions and systems, discourage foreign investment, and distort international capital flows".

There are other implications. A non-compliant country may not be able to provide international law enforcement with useful information such as customer identification and transactions records to assist in tracing the origins of transaction monies. In 2009, the G20 Working Group on Reinforcing International Cooperation and Promoting Integrity in Financial Markets [10] indicated that countries should implement measures that protect the global financial system from uncooperative or non-compliant countries with FATF recommendations that create risks of illicit financial system. In conclusion, non-compliance with the FATF recommendation means a heightened risk for a country's financial systems, reputation, and its interests in dealing with other countries in an extremely globalised world.

\section{Factors Affecting Compliance}

The previous section analysed and compared the extent of compliance of the USA, the UK, Australia and the UAE with the FATF AML/CFT recommendations. The $\mathrm{UAE}$ is the least compliant with the AML/CFT recommendations which is perhaps not surprising. The FATF requirements presuppose the existence of a sophisticated good governance environment and an advanced information technology (IT) infrastructure being established. Good corporate governance is a western creation that relies in the modern environment on the availability of appropriate human resources and developed policies and procedures, and ethical standards, together with audit capability and capacity. This may not be readily available in a developing economy at a stage in advancing its specific economy in a global environment. The compliance obligation to FATF may require some compromise when it comes to a non-western economy but such compromise must not open the door to criminal elements to launder money at the expense of other jurisdictions. This section examines some of the underlying cultural considerations and culture-specific ethical issues that affect the extent of the UAE compliance, and how cultural and ethical considerations may affect good governance and the establishment of shared codes of practice. This examination covers religious, cultural, socio-economic and financial factors that appear to be important in the case of the UAE.

\subsection{Ethical Behaviour, Good Governance and Culture}

The Internet has brought to the fore and highlighted many new situations fraught with ethical considerations. These considerations arise because the Internet provides so many options for communication and options to access global information resources from a single point of access. It is exactly this power and its potential for misuse that has attracted the attention of national and international organisations interested in the use of the Internet for the common good. Of specific note in this regard is SIG9.2.2 [11], the IFIP Special Interest Group on a Framework for Ethics of Computing, which has been working in this domain for 20 years and which in 1999 published an influential monograph that has direct relevance to the work described in this paper, "Ethics 
and the Governance of the Internet" [12]. It is likewise the opportunities provided by the Internet that are exploited by money launderers, giving rise to the evocative phrase "the big cyber-laundering machine" [13].

One of the most pervasive ethical considerations highlighted by global information access concerns the tension between the need for privacy and anonymity on the one hand and the need for accountability on the other $[14,15]$. This particular conflict of course transcends national and cultural boundaries, but balancing privacy and anonymity against accountability is pivotal in attempts to combat money laundering globally [14]. As discussed below and in sections 3.2 and 3.3, it presents an especially acute challenge for emerging and developing economies. The UAE at least is progressively addressing the issue.

AML presents a prime example of this conflict between privacy (and anonymity) and accountability, at both the international level where AML efforts rely on identifying the nature of trans-national financial transactions, and also at the local level where identifying suspicious transactions is reliant on reports to the relevant national FIU. There are of course other IT-related ethical issues which are just as relevant but here the focus will be culture-specific. For example, the role of women in society differs markedly across cultures and this relates at a practical level to issues such as the 'digital divide' - not between developing and developed states in this case, but within communities - and open access to the Internet. Open access to the Internet is a point of focus [12].

In Section 3.3 we examine the role played by the Hawala system in the UAE which differentiates it from the other three jurisdictions analysed. Hawala is an honourbased system which is pervasive in many Islamic economies throughout the world. It is used to transfer money or value between people in a local community without any interaction with financial institutions. It has virtually no parallel in western culture and presents a direct challenge to AML efforts. In the case of the UAE, this challenge is addressed through a Hawala broker registration scheme which is, however, still voluntary.

There is another, more complex, example of cross-cultural difference with significant underlying ethical considerations which is examined in Section 3.2. It relates directly to the fight against terrorism on the one hand and society's obligation to provide for the needy on the other. Crimm [16] indicates that implementing the FATF strict standards on AML/CFT can affect the effectiveness and the remit of Islamic charities, and consequently 'cut off' financial support to the needy. This issue does not arise in western culture where company legislation and income tax legislation have historically resulted in careful regulation of charitable institutions.

These two examples illustrate some of the difficulties that face the international community in establishing internationally shared and accepted codes of practice. While establishing principles of good governance is paramount, whether with respect to AML or with regard to international financial markets or whatever, the difficulty is in the detail. In other words, establishing principles of good governance will most likely involve the reconciliation of local cultural and ethical differences if there is to be internationally shared and accepted codes of practice. This could involve compromise so as to accommodate cultural differences and ethical standards. The case of the UAE's progressive alignment with FATF is a salutary example of such reconciliation. 
These dilemmas lead naturally to questions regarding the advantages and disadvantages, and the feasibility in general, of constructing a single international framework based on a consensus of divergent views. There is evidently no easy way to do so. Experience shows that building such a consensus is a slow process, and it is important to accept this at the outset of such attempts, in order to avoid premature acceptance of failure. Success requires a willingness of all parties to cooperate and to reconcile differences. Experience also shows that the path to global consensus requires the participation not only of champion international agencies but also of local and regional bodies as well as other stakeholders. The latter is paradoxically made possible by the nature of the Internet - its global nature, the very issue that prompts attempts to achieve the consensus - and the vested interests of non-regulatory, commercial stakeholders. Two recent examples of achieving some degree of such a consensus through regional bodies are the reconciliation of the European Union (EU) and USA approaches to the protection of privacy [12] and cooperation between FATF and regional FATF-style bodies (APG, CFATF, MONEYVAL, GAFISUD, MENAFATF, EAG, ESAAMLG, GIABA ${ }^{4}$ ) [17]. The work undertaken by the FATF and the FATFstyle regional bodies facilitates similar or comparable approaches for implementing AML/CFT systems. While the FATF recommendations are in many cases not fully implemented by the member countries, these recommendations are still considered as an important framework for countries to use in order to counter money laundering and terrorist financing. The focus here is to observe the advantages that the FATF experience creates for proceeding towards a harmonised AML/CFT system and how it has succeeded in bringing these different countries and organisations to agree in principle on international standards for AML/CFT systems.

\subsection{Religious and Cultural Factors}

The UAE's culture has developed from a strong belief in Islam which governs people's way of life, behaviour and decisions [18]. This has had a significant impact on UAE culture. The UAE culture is accordingly in many ways significantly different from the culture in Australia, the UK and the USA.

The founding members of the FATF - which did not include the UAE - such as Australia, the UK and the USA, have unavoidably left their cultural imprint on the organisation and its operations. This has some natural consequences when it comes to FATF evaluations. Johnston and Carrington (2006) [19] indicate that there is a problem when the FATF do a mutual assessment evaluation of the AML/CFT systems in member countries. This problem is how to implement FATF standards that have been structured in the context of developed economies and apply them to the financial markets of emerging and developing economies. These developing economies [19] typically comprise a substantially different culture and history to that of developed economies. Johnston and Carrington note that trying to impose measures which are unsuitable for developing countries may lead to non-compliance with the FATF standards [19]. Kanatas and Stefanadis (2005) [20] note that culture and legal systems support each other and that economic development and financial structures are affected not only by a country's legal system but also by its culture. They show that

${ }^{4}$ The full titles of all these organisations are given on the Members and Observers page of the FATF website. 
the development of a country's legal and financial systems is related to its religious beliefs. They note that culture is "the engine of economic prosperity and growth and a critical factor in the development of financial markets". When people talk about culture, they talk about a way of life, what people believe, and how they apply that to develop their regulations, organisations and institutions. Kwok and Tadesse (2005) [21] argue that countries differ in the configuration of their financial systems because they are different in terms of their national cultures.

According to the US Department of State (2007), Islam is practiced by $96 \%$ of the population in the UAE [22], making it a dominant influence on the country. Islam prohibits any activity funded by money derived from unlawful trade or ill-gotten property and prohibits using illegal money for charities [23]. Money gained from gambling and bank interest is prohibited in Islam [23]. This is in marked contrast to normal practice in Australia, the UK and the USA.

While there is no income tax in the UAE, Muslims are required as a part of their religion to "[fulfill] the God right through paying money 'Zakat' to charities or to the needy people" [23]. Charities play an important role in Muslim practices. Crimm (2008) [16] noted that "as Islam places a high value on compassion, wealth redistributions, social justice, and supporting and enhancing fellow humans, both philanthropy and charity play crucial roles for Muslims and their civil societies". The FATF special recommendation VIII indicates that countries should have effective laws and regulations concerning non-profit organisations that can be misused for the financing of terrorism including taking a risk-based approach that identifies the aims of the organisation, its size and the amount of money it handles $[1,24]$. The challenge is in identifying what kind of activities constitutes terrorism and whether financing some such activities would be considered as the financing of terrorism. The World Bank (2006) [25] noted that while countries have agreed on combating the financing of terrorism, the "meaning of terrorism is not universally accepted due to significant political, religious and national implications that differ from country to country". Crimm [16] indicated that implementing the FATF strict standards on AML/CFT could affect the extent of Muslim charities and consequently effectively 'cut off' financial support to the needy. Many countries such as the UAE have imposed some obligations on charitable organisations to protect them from misuse. All charitable organisations in the UAE are regulated and monitored by the Ministry of Social Affairs [2]. The UAE also specifies legitimate channels for charities to transfer money outside the country in order to minimise possible use of these funds for illegal purposes. In 2002, the UAE government regulated that all licensed charitable organisations wishing to transfer money overseas, must do so through either: the Red Crescent Authority, the Zayed Charitable Foundation, or the Muhammad Bin Rashid Charitable Trust [2]. This allows people to make charitable donations whose destination can be monitored.

Islam's prohibition of bank interest means that an important service provided by Islamic banking is the buying and selling of goods without interest. For example, if a person wants to buy a car, they do not give the money directly to the seller. Instead, the bank buys the car and resells it to the buyer/ bank customer. This practice is called Murabaha [26] and is pervasive throughout the UAE banking sector. It is noted that while some nonIslamic banks in Australia for instance have started to recognise the need for such services, this is again in marked contrast to normal practice in Australia, the UK and the USA.

The UAE is a cash-based economy in which carrying large cash amounts is a normal practice and this makes it more difficult to impose requirements concerning 
reporting large cash transactions. Imposing regulations (for instance, requiring all large transactions to be reported) in such circumstances is very difficult if not impossible. While many consider this to be a good cultural trait, it is problematic for the purpose of analysing the money cycle. Finally, the UAE is a society based on strong homogeneity [27] which is characterised by strong extended family relationships and close family ties [28]. There is a concern here especially when applying the FATF standards that relate to customer due diligence. For instance, if a person goes to a bank to conduct a transaction and finds that he/she knows the bank's employee, it is quite likely that the employee will not undertake due diligence procedures. (In fact, this practice is not limited to only the UAE culture although it is considerably more prevalent in the UAE than some other countries. Bedi and Acharya (2005) [29] note that personal relationships "can lead to poor compliance [with AML] standards as many US Private Banks have found out".) In the UAE, carrying large sums of cash and purchasing properties and expensive products by cash is normal [4]. The US Department of State [2] noted that according to the UAE, "[c]ustoms officials, police, and judicial authorities tend to not regard large cash imports as potentially suspicious or criminal type activities, arguing that the UAE is a cash-based economy, and it is not unusual for people to carry significant sums of cash".

\subsection{Socio-economic and Financial Factors}

The US Department of State (2007) indicates that oil makes up most of the UAE export earnings and it dominates the economy [22]. Oil provides wealth to the country and its people.

One of the socio-economic factors that affects the UAE financial system and differentiates it from the three other countries in this study is the use of the Hawala system. The Hawala system is used to transfer money or value between people in a local community without any interaction with financial institutions. Viles (2008) [30] defines Hawala as "a system by which people in geographically remote areas can give things of value to each other, without the physical (and, now, without the electronic) conveyance of money". The UAE has established regulations in relation to Hawala which require that Hawaladars should register themselves and then they are recognized as Hawala Brokers [31]. The UAE intends to ensure that the Hawala brokers provide details of money transfers and report any suspicious transfers. The registration is still voluntary and UAE authorities have no legal power to examine Hawaladars for non-compliance.

Australia, the UK and the USA are all recognised as developed economies, while the UAE is an emerging economy. In the UAE, in contrast to Australia, the UK and the USA, there is no tax on income and this has at least two interesting implications. The first is that the motivation for money laundering in order to achieve tax avoidance is absent. The second is that the cycle of money is harder to trace as a result of not having to report income. The obligatory reporting of income in other countries enables the flow of money to be more easily followed. While the UAE requires financial institutions to report any transactions that are unusually large for a given account with no legal purpose or reasonable or economic grounds [32], there is no general requirement to report income by companies or by individuals.

The financial systems in Australia, the UK and the USA are very similar and are dominated by their stock markets [21] and although UAE financial systems have 
some similarities with these countries, there are important differences. These differences play an important role in how the country implements its AML/CFT system.

\subsection{Summary}

It is inevitable that achieving the good governance requirements implicit in the FATF recommendations is difficult; this is due at least in part to different ethical and cultural values internationally. It is nonetheless of paramount importance in combating money laundering, terrorism and organised criminal activity to address this challenge; doing so requires a careful, country by country, consideration of local factors and values. Overall, in the context of the four countries examined in this study, it is submitted that further steps are needed by both the UAE and the FATF in order to achieve a higher degree of compliance with the FATF recommendations.

\section{Conclusion}

This paper has investigated the implementation of the FATF recommendations by Australia, the UAE, the UK and the USA. Gaps in compliance were identified for the core and key recommendations for three of the four countries studied and the analysis indicates that there are additional steps that need to be taken by Australia, the UAE and the USA to address the identified deficiencies. The AML/CFT system of the UAE in particular is least compliant with the recommendations. The paper has examined some of the underlying cultural considerations, and culture-specific and ethical issues that affect the extent of the UAE compliance, and how cultural and ethical considerations may affect good governance in general and the establishment of shared codes of practice. The paper has examined religious, cultural, socio-economic and financial factors that appear to be important in the case of the UAE. These factors represent a real challenge to any country such as the UAE when implementing its regulations and financial institutions. Given the global and widespread nature of money laundering, it is vital that local and international communities cooperate to meet these challenges.

Acknowledgement. We gratefully acknowledge the comments of our anonymous reviewers who have assisted considerably in focusing our analysis on how ethical and cultural considerations relate to the development of an internationally shared approach and a consensual international framework.

\section{References}

1. FATF, http://www. fatf-gafi.org/dataoecd/7/42/38896285.pdf

2. US Department of State, http://www.state.gov/documents/organization/120055.pdf

3. FATF, http://www. fatf-gafi.org/dataoecd/22/38/35509034.pdf

4. FATF, http://www. fatf-gafi.org/dataoecd/47/55/41721938.pdf

5. FATF, http://www. fatf-gafi.org/dataoecd/44/9/37101772.pdf

6. FATF, http://www. fatf-gafi.org/dataoecd/44/8/44048060.pdf

7. FATF, http://www. fatf-gafi.org/dataoecd/44/12/37101706.pdf

8. Alkaabi, A., Mohay, G., McCullagh, A., Chantler, N.: A Comparative Analysis of the Extent of Money Laundering in Australia, UAE, UK and the USA. In: Finance and Corporate Governance Conference, Melbourne (2010), http://ssrn.com/abstract=1539843 
9. International Monetary Fund, http: / /www.imf.org/external/np/exr/facts/aml.htm

10. G20, http://www.g20.org/Documents/g20_wg2_010409.pdf

11. IFIP-SIG9.2.2, http: //www. info. fundp.ac.be/ jbl/IFIP/cadresIFIP.html

12. Berleur, J., Duquenoy, P., Whitehouse, D. (eds.): Ethics and the Governance of the Internet, IFIP SIG9.2.2 IFIP Framework for Ethics and Computing (1999),

http: / / www. info. fundp.ac.be/ bl/IFIP/

Ethics_and_Internet_Governance.pdf

13. Lovet, G.: Fighting Cybercrime: Technical, juridical and ethical challenges. In: Virus Bulletin Conference, Geneva, pp. 63-76 (2009)

14. Bynum, T.: http://plato.stanford.edu/archives/win2008/entries/ ethics-computer/

15. Nissenbaum, H.: The Meaning of Anonymity in an Information Age. The Information Society $15,141-144$ (1999)

16. Crimm, N.J.: The Moral Hazard of Anti-Terrorism Financing Measures: A Potential to Compromise Civil Societies and National Interests: Islamic Law and Law of the Muslim World Paper No. 08-32. Wake Forest Law Review (2008)

17. FATF, http: //www. fatf-gafi.org/pages / 0,3417, en_32250379_32236869_1_1_1_1_1,00.html

18. ArticlesBase, http://www.articlesbase.com/travel-tips-articles/ culture-tips-for-dubai-travel-208239.html

19. Johnston, R.B., Carrington, I.: Protecting the financial system from abuse: Challenges to banks in implementing AML/CFT standards. Journal of Money Laundering Control 9, 48-61 (2006)

20. Kanatas, G., Stefanadis, C.: Culture, Financial Development, and Economic Growth. Preliminary Version (2005), http: / finance.eller.arizona.edu/documents / seminars/2004-5/CStefanadis.Culture04-05.pdf

21. Kwok, C.C.Y., Tadesse, S.: National Culture and Financial Systems. William Davidson Institute Working Paper No. 884 (2005), SSRN http://ssrn.com/abstract= 1017605, http: / / ssrn. com/abstract $=1017605$

22. US Department of State, http://www.state.gov/r/pa/ei/bgn/5444.htm

23. Alagha, S.: Money Laundering from Islamic perspective. Journal of Money Laundering Control 10, 406-411 (2007)

24. FATF, http://www. fatf-gafi.org/dataoecd/8/17/34849466.pdf

25. World Bank: Reference Guide to Anti-Money Laundering and Combating the Financing of Terrorism. The International Bank for Reconstruction and Development/The World Bank/The International Monetary Fund, Washington DC (2006)

26. HSBC, http: //www. hsbcamanah.com/

27. Sindelar, H.R., Peterson, J.E. (eds.): Crosscurrents in the Gulf. Routledge, Washington (1988)

28. Swadi, H.: Child Mental Health Services in the United Arab Emirates. Child Psychology and Psychiatry Review 4(1), 27-29 (1999)

29. Bedi, R., Acharya, A.: AML/CFT - New Policy Initiatives. PriceWaterhouseCoopers and Institute of Defence and Strategic Studies. PWC-IDSS Thought Leadership Series (July 2005), http: / /www.c-cft.org/publication/pdf/PwC-IDSS_200507.pdf

30. Viles, T.: Hawala, hysteria and hegemony. Journal of Money Laundering Control 11, 25 33 (2008)

31. Central Bank of the UAE, http: / / www . centralbank . ae / AMLSU . php

32. UAE Government, http: / / www . centralbank. ae/pdf / AMLSU/

RegulationSummary-2005.pdf 